\title{
Extract prepared from the leaves of Ocimum basilicum inhibits the entry of Zika virus
}

\author{
P. SINGH, P. CHAKRABORTY, D.-H. HE, A. MERGIA*
}

Department of Infectious Disease and Immunology, University of Florida, 1945 SW 16th Avenue, Gainesville, FL 32611, USA

Received January 11, 2019; revised April 12, 2019; accepted April 15, 2019

\begin{abstract}
Summary. - The recent Zika virus (ZIKV) outbreaks and rapid spread in tropical Latin America since introduction to Brazil in 2014, and now appearing cases in the USA, are alarming. World Health Organization (WHO) has considered transmission of ZIKV, a serious public health problem because of the increasing number of outbreaks. There are currently no drugs approved for the treatment of ZIKV infection. Discovery of safe and effective drugs are hampered by the risk in treating pregnant woman and toxicity to the fetus. Sweet basil, known as Ocimum basilicum in the scientific community, is a very well-known medicinal herb. Numerous studies have documented its beneficial activity against a great variety of human pathogens ranging from bacteria and virus to fungus and protozoans. Although, basil extracts and oils have been tested successfully against other viruses, its application to tackle ZIKV infection has not been exploited at all. In this study, we report for the first time that highly diluted ethanol extracts prepared from basil leaves can effectively inhibit ZIKV replication in Vero E6 cells with a half maximal inhibitory concentration $\left(\mathrm{IC}_{50}\right)$ value of 1:134. The diluted extract as well as the amount of ethanol that goes into its preparation have been found to be completely non-toxic to the above mentioned cell line. The extract seems to inhibit the virus at the step of attachment and entry into the host cell. The specific inhibition of ZIKV observed using the basil leaf extract suggests a new alternative mode of treatment against flavivirus.
\end{abstract}

Keywords: Zika virus; basil extract; antiviral

\section{Introduction}

Zika virus (ZIKV) belonging to the Flaviviridae family, the Flavivirus genus has been associated with several outbreaks in different parts of the world (Oehler et al., 2014; Cao-Lormeau et al., 2016; Ventura et al., 2016; Aliota et al., 2017). Although, ZIKV was initially discovered in the year 1947 from a Rhesus monkey in the African continent, in recent history it has spread from the Asia to Latin and South America; the most notable one was the 2015 epidemic in Brazil. Risk countries need to have in place adequate preparation for managing the patients. There are several

"Corresponding author. E-mail: mergiaa@ufl.edu; phone: +352294-4139.

Abbreviations: ZIKV = Zika virus; $\mathrm{WHO}=$ World Health Organization ongoing drug developments in progress to establish effective anti ZIKV therapeutics (Barrows et al., 2016; Adcock et al., 2017). However, there are currently no effective drugs approved for ZIKV infection. A major hurdle in the use of drug based therapeutics for ZIKV is the risk to the pregnant women and the developing fetus. Natural products such as medicinal plants offer safe and inexpensive option for developing anti-ZIKV agents. Basil (Ocimum basilicum) is a culinary herb belonging to the family that has several health benefits (Pandey et al., 2014). Essential oils obtained from basil have been reported to have strong inhibitory activity against a wide range of pathogenic microorganisms (Suppakul et al., 2003; Chiang et al., 2005; Khalil, 2013). Basil extracts, thus, provide an attractive mode of treatment strategy against many emerging pathogens that demand viable therapeutic options. The application of extracts and purified components of basil as possible antiviral agents has already been reported (Chiang et al., 2005). The extracts and specific 
purified compounds have shown broad-spectrum activity against both DNA and RNA viruses. However, basil leaves have not been tested directly on Zika virus. The potential use of basil extract as an anti-ZIKV drug merits examination. Here, we report for the first time that extract prepared from basil leaves can be used as an inhibitory agent to control ZIKV replication. The effect of the extract on ZIKV entry has also been investigated.

\section{Materials and Methods}

Preparation of extracts. Dried basil (O. basilicum) leaves were crushed into powdered form and extract was done in $50 \%$ ethanol for $48 \mathrm{~h}$ at $4^{\circ} \mathrm{C}$. The whole extract was centrifuged at 10,000 rpm for $5 \mathrm{~min}$; the supernatant was collected and filtered using $0.45 \mu \mathrm{m}$ acrodisc syringe filter membrane (Pall Corporation, Life Sciences). The filtered extract was serially diluted from a ratio of 1:16 to 1:512 with Dulbecco's modified Eagle's medium (DMEM) and tested for anti-ZIKV activity.

Virus and cell line. African green monkey (Cercopithecus aethiops) kidney tissue cell line Vero E6 clone was obtained from the American Type Culture Collection (ATCC CCL-81, USA). Vero cells were grown in DMEM (Gibco, USA), supplemented with $10 \%$ fetal calf serum, 100 units/ml penicillin $\mathrm{G}$ and $100 \mathrm{mg} / \mathrm{l}$ streptomycin at $37^{\circ} \mathrm{C}$ in a humidified atmosphere of $5 \% \mathrm{CO}_{2}$. The Puerto Rico ZIKV strain PRVABC59 (Zeptomatrix, USA) was propagated in Vero cells and virus stock was stored at $-80^{\circ} \mathrm{C}$ for future use. Cytopathic effects were observed with an inverted light microscope (Zeiss, USA) at 1, 3, and 5 days post-virus inoculation. The virus stock was titrated by infecting Vero cells followed by plaque assay as described previously (Chan et al., 2016).

Cell toxicity assay. Vero cells were cultured in 96-well plate at a density of $1 \times 10^{5}$ cells/ml. Basil extracts at different dilutions (1:16, $1: 32,1: 64,1: 128,1: 256,1: 512)$ prepared in DMEM were added in triplicates to each culture well. The cells were incubated for three different time periods of 24,48 , and $72 \mathrm{~h}$. Untreated cells were used as control. Cytotoxicity of basil extract was determined using the MTT (3-(4, 5-dimethylthiazolyl-2)-2, 5-diphenyltetrazolium bromide) calorimetric assay as previously described (Green et al., 1984). The percentage of cell viability was calculated using the following equation: $\%$ relative cell viability $=(1-\mathrm{OD}$ treated $/ \mathrm{OD}$ control) $\mathrm{x} 100$. The concentration of basil extract producing $50 \%$ inhibition was calculated according to Roy et al. (2013). Data from three independent experiments have been plotted and standard error of mean shown.

Antiviral assay. The anti-ZIKV activity of basil extract was evaluated using Vero cells. Briefly, cells were seeded at a density of $1.5 \times 10^{5}$ in 12 -well plate and incubated for $24 \mathrm{~h}$ at $37^{\circ} \mathrm{C}$. Different dilutions of the basil extract in DMEM were mixed with $10^{5}$ focus forming units of ZIKV PRVABC59 and kept at room temperature for $1 \mathrm{~h}$. After $1 \mathrm{~h}$ incubation, the mixture of ZIKV and basil extract were added to the Vero cell culture and again incubated for an $1 \mathrm{~h}$ at $37^{\circ} \mathrm{C}$ for viral absorption. Untreated cells were used as control. DMEM containing 2\% fetal bovine serum (FBS) and $1 \%$ carboxymethylcellulose sodium salt (Sigma-Aldrich) were added to the wells and incubated for 4-5 days. Cells were then fixed with $10 \%$ formaldehyde and stained with $1 \%$ crystal violet. Plaques were counted and compared to the control. The percentage of inhibition in viral replication due to the treatment with different dilutions of basil extract was expressed as relative foci number with respect to the untreated control. It was calculated as follows: [(number of plaques form peptide treated cells/number of plaques form control cells) $x$ 100]. The data from three independent experiments were plotted and standard error of mean is shown.

Pre- and post-infection activity of basil extract. Vero cells were treated with the different dilutions (1:16, 1:32, 1:64, 1:128, 1:256, 1:512) of the basil extract prepared in DMEM before (pre-infection) or after (post-infection) being infected with ZIKV. In pre-infection, dilutions of the extract were added to monolayer of Vero cells and the cells were then incubated for $2 \mathrm{~h}$ at $37^{\circ} \mathrm{C}$. The media containing the extract was removed and the cells were then washed twice with pre-warmed PBS to remove all the traces of the extract and infected with $10^{5}$ focus forming units of ZIKV. After allowing for viral absorption for $1 \mathrm{~h}$ at $37^{\circ} \mathrm{C}$, DMEM containing 2\% FBS and $1 \%$ carboxymethylcellulose sodium salt (Sigma-Aldrich) were added to the wells and incubated for 4-5 days. The viral titer was then quantified by plaque assay. In the scenario of post-infection, monolayer of Vero cells were first infected with $10^{5} \mathrm{PFU}$ of ZIKV. After an incubation period of $4 \mathrm{~h}$, different concentrations of basil extract were added and incubated further for $2 \mathrm{~h}$. The media containing the extract was removed, cells were washed twice with pre-warmed PBS, and fresh complete media was added. The levels of viral replication were determined by plaque assay similar to pre-infection. Untreated cells were used as control in both the infection procedures.

\section{Results}

\section{Anti-ZIKV activity of basil extract}

In order to evaluate the anti ZIKV activity of the prepared basil extract, different serial dilutions of the extract were tested. Vero cells were infected with $10^{5}$ PFU of ZIKV mixed with the prepared dilutions $(1: 16,1: 32,1: 64,1: 128$, $1: 256,1: 512)$ of basil extract in DMEM and the level of virus infection was monitored by plaque assay. As shown in Fig. 1, the inhibition of ZIKV measured as relative foci number is dose dependent. ZIKV inhibition ranged from $97 \%$ to $13 \%$ of the untreated control value depending on the extract dilution factor. The viral titer decreases in a dose dependent manner with a half maximal inhibitory concentration $\left(\mathrm{IC}_{50}\right)$ value of 1:134 for the cell line tested. At the highest concentration (1:16 dilution), we have observed the most effective inhibition showing $97 \%$ reduction in virus infectivity 


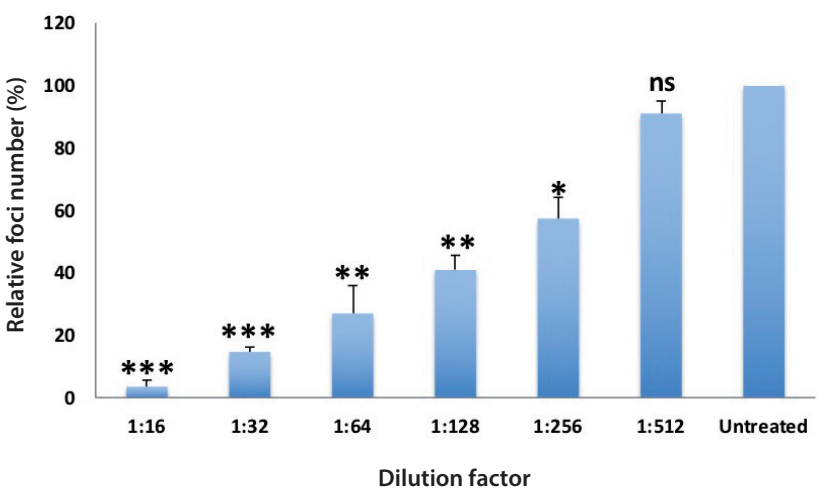

Fig. 1

Dose related effect of basil leaf extract on Zika virus

Different dilutions of the basil extract (1:16, 1:32, 1:64, 1:128, 1:256, 1:512) prepared in DMEM mixed with $10^{5}$ focus forming units of ZIKV PRVABC59 were added to Vero E6 cells. After an incubation period of 4-5 days, the inhibitory effect was evaluated by plaque assay. The $\mathrm{x}$-axis indicates the dilution of the basil extract used and the $y$-axis shows the number of foci relative to the untreated control. Data are the mean \pm SEM of three independent experiments. Test for significance was performed with a two tailed unpaired Student's $t$-test compared to the control. ${ }^{*} \mathrm{p}<0.05,{ }^{* *} \mathrm{p}<0.005$, ${ }^{* * *} \mathrm{p}<0.0005 ; \mathrm{ns}=$ not significant.

relative to the control value. Thus, these results suggest that basil extract can effectively inhibit virus infection, showing it has potent antiviral activity.

Basil components comprising of R-(-)-2-methyl-5(prop1-en-2-yl)-cycloheX-2-enone (also called (-) carvone) and S-(+)-2-methyl-5-(prop-1-en-2-yl)-cycloheX-2-enone (also called $(+)$ carvone), (2E)-3;7-dimethylocta-2;6 dien-l-ol (also called trans-geraniol) in combination with at least one more chemical chosen among essential oils components were shown to have antiviral activity for some viruses (Marwat et al., 2011; Gavanji, 2015). These observations by other research groups indicate that multiple components of basil extract are required for antiviral activity. So, we wanted to explore whether these chemical alone or in combination can prevent the growth of ZIKV. We have tested $(R)-(-)$-carvone $98 \%(1 \mathrm{ml}),(S)-(+)$-carvone $96 \%(2 \mathrm{ml})$, trans-geraniol $98 \%(1 \mathrm{ml})$, apigenin $95 \%[100 \mu \mathrm{l}$ $(10 \mathrm{mg} / \mathrm{ml})]$, linalool $97 \%(800 \mu \mathrm{l})$, or ursolic acid $100 \mathrm{ul}$ $(50 \mathrm{mg} / \mathrm{ml})$ individually or as a mixture to determine their anti ZIKV activity. Our results revealed that these basil components, individually or together, have no efficacy on ZIKV (data not shown). This observation suggests that additional basil component(s) that work alone or in concert with above tested compounds are required for impeding ZIKV replication.

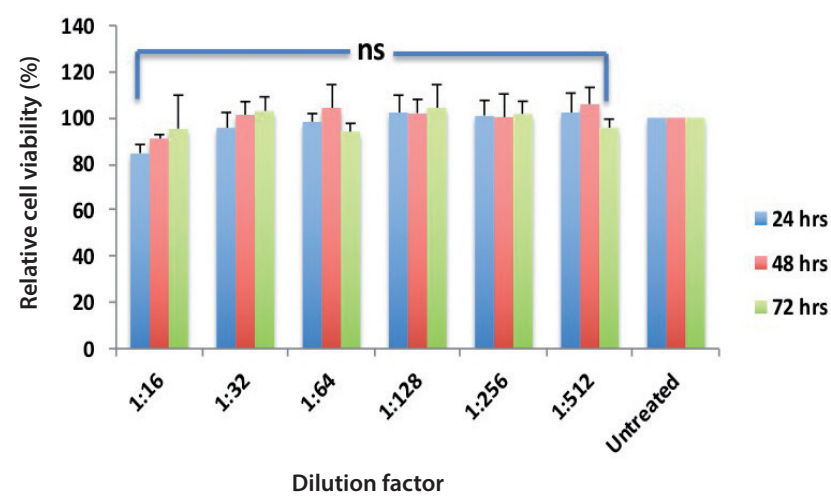

Fig. 2

Time and dose dependent effect of basil leaf extract on Vero cells Basil extract at the following dilutions (1:16, 1:32, 1:64, 1:128, 1:256, 1:512) prepared in DMEM were added to Vero E6 cells. After different incubation periods of 24,48 and $72 \mathrm{~h}$, the effect was analyzed by MTT assay. The $\mathrm{x}$-axis indicates the dilution of the basil extract used and the $\mathrm{y}$-axis shows the percent cell viability relative to the untreated control. Data are the mean \pm SEM of three independent experiments. Test for significance was performed with a two tailed unpaired Student's $t$-test compared to the control; ns = not significant.

\section{Growth characteristics of the basil extract treated Vero E6 cells}

The antiviral activity demonstrated by crude basil extract advocate its use as a potential drug against ZIKV. In order to be used as an antiviral drug, the extract needs to have minimal side effect inside the host. To confirm that the basil extract has no effect on the normal growth of Vero E6 cells, MTT assay was performed with the extract at 24, 48, and $72 \mathrm{~h}$ post treatment. The results in Fig. 2 showed that all the dilutions of the crude basil extract concentration used to monitor antiviral activity were not toxic to the Vero cells, even after $72 \mathrm{~h}$ of incubation. This suggests that the observed inhibition of ZIKV virus was not due to non-specific, pleotropic effect of the basil extract on the Vero cells.

\section{Toxicity of ethanol on ZIKV}

In order to determine that the antiviral activity of basil extract was not due to the presence of ethanol used for extraction, different dilutions of $50 \%$ ethanol were tested on ZIKV by plaque assay. Fifty percent ethanol was diluted in the same manner as the original basil extract, serially from 1:16 to 1:512 in DMEM. Each dilution of ethanol was mixed with ZIKV for $1 \mathrm{~h}$ and the mixture was then used to infect Vero cells. The infected cells were then fixed with $10 \%$ formaldehyde and stained with $1 \%$ crystal violet for plaque visualization. The viral growth has been reported as relative 


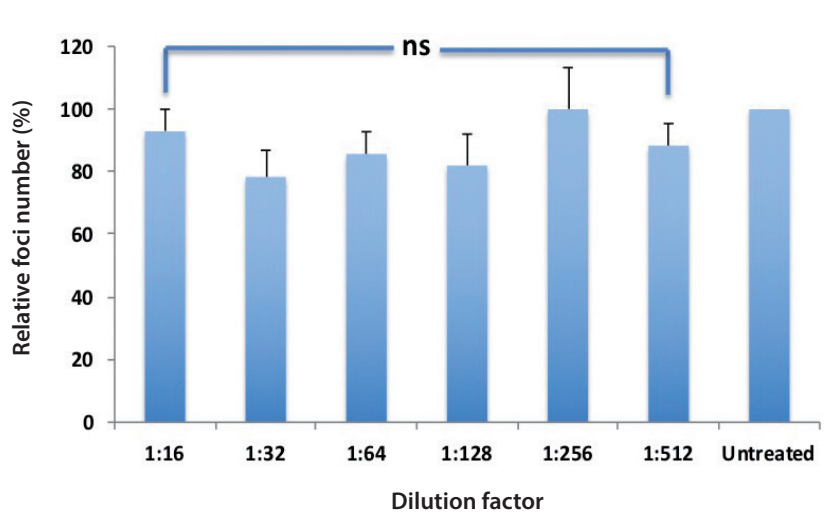

Fig.3

Non-toxicity of the ethanol used in basil extract preparation Different dilutions of $50 \%$ ethanol (1:16, 1:32, 1:64, 1:128, 1:256, 1:512) prepared in DMEM were mixed with Zika virus and added to Vero E6 cells. After an incubation period of $4-5$ days, the inhibitory effect was evaluated by plaque assay. The $\mathrm{x}$-axis indicates the dilution of the ethanol used and the $y$-axis shows the number of foci relative to the untreated control. Data are the mean \pm SEM of three independent experiments. Test for significance was performed with a two tailed unpaired Student's $t$-test compared to the control; ns = not significant.

foci number with respect to the untreated control. As shown in Fig. 3, there was no statistically significant inhibition of ZIKV by the amount of ethanol used to determine the antiviral activity of basil extract. These results suggest that the inhibition is a direct effect of the basil products and not the ethanol used for extraction.

\section{Basil extract is inhibiting ZIKV entry}

The anti-ZIKV activity of basil extract was tested before and after infection to determine whether the extract is affecting the entry of the virus into the host cell. For pre-infection treatment, Vero cells were treated with different dilutions of the basil extract for $2 \mathrm{~h}$. The extract containing medium was removed and the cells were washed thoroughly before being infected by ZIKV. In a separate experiment to analyze the post-infection effect of basil extract, Vero cells were first infected with the same units of ZIKV and later different concentrations of basil extract were added and incubated for $2 \mathrm{~h}$. The extract was removed, cells were washed with PBS and fresh complete media was added. The levels of viral replication in both pre- and post-infected cells were determined by plaque assay with respect to the control (Fig. 4). As can be seen from the graph, the number of plaques in cells pre-treated with basil extract were at the same level as that post-treated to ZIKV infection. Statistical analysis further confirmed the null hypothesis. Thus, the level of ZIKV replication was comparable, whether the basil extract was

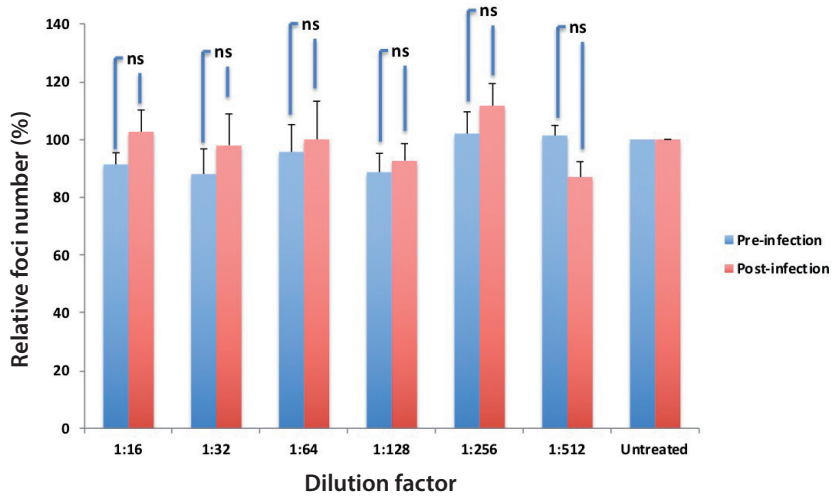

Fig. 4

The basil extract is affecting entry of Zika virus into the host cell Vero cells were treated with (1:16, 1:32, 1:64, 1:128, 1:256, 1:512) dilutions of basil extract before (pre-infection) or after (post-infection) being infected with Zika virus. In both the cases, the extract was washed away after $2 \mathrm{~h}$. After an incubation period of 4-5 days, the inhibitory effect was evaluated by plaque assay. The $\mathrm{x}$-axis indicates the dilution of the extract and the $y$-axis shows the number of foci relative to the untreated control. Data are the mean \pm SEM of three independent experiments. Test for significance was performed with a two tailed unpaired Student's $t$-test compared to the control; ns = not significant.

added before or after virus infection. From this experiment, we can conclude the effects of the extract during the infection process. Absence of ZIKV inhibition in basil pre-treated cells suggests that the extract is not modifying the necessary receptors for viral attachment to the target cell. This property of the basil extract is physiologically better, since, in the absence of receptor modulation it is expected to have minimal side effects, if any, a very important requirement for an antiviral drug. There was also no effect on the ZIKV lifecycle when we added the extract for $2 \mathrm{~h}$ post-infection and then removed it. This observation strengthens the conclusion that the basil extract is inhibiting ZIKV at the viral attachment and entry by blocking the host-pathogen interaction.

\section{Discussion}

Ocimum basilicum is a very popular herb used across many different countries in diet and as a folk remedy for its medicinal values. Basil can be considered as a natural blessing whose full potential as a therapeutic reagent is yet to be explored completely. In the present study, the antiviral potential of basil against ZIKV has been demonstrated. Crude ethanol extract prepared from dried basil leaves has been found to inhibit the growth of ZIKV in Vero cells. The inhibition is dose dependent with an $\mathrm{IC}_{50}$ value observed at the dilution of 1:134. The ability of the prepared basil extract to inhibit ZIKV replication at such high dilution bodes well 
for its future application as an antiviral drug. Moreover, both the extract as well as the amount of ethanol used for its preparation have been found to be absolutely non-toxic to the cells, an essential feature for any medicine. Carvone, trans-geraniol, apigenin, linalool and ursolic acid are plant products previously reported to have antiviral activity (Chiang et al., 2005; Marwat et al., 2011; Gavanji, 2015). All these compounds, alone or in mixture, have been tested against ZIKV and it was observed that they were unable to exert any effect on ZIKV propagation. Thus, the basil extract we have prepared must have other novel constituents responsible for the perceived anti ZIKV activity. Identification of the component(s) is a scope for future research.

In order to investigate how basil extract inhibits infection, a time-course experiment was done with pre- and post-infection of Vero cells by ZIKV with various doses of the extract. Interestingly, ZIKV replication was not affected by the time-point of addition that is before or after infection by ZIKV. This indicates that its mode of action is to inhibit the virus at the step of receptor attachment and entry into the host cell. A study by Barrows et al. (2016) has shown that drugs such as bortezomib and mycophenolic acid can act as inhibitors of ZIKV infection in human HuH-7 cells (Barrows et al., 2016). However, these drugs have potential side effects of being teratogenic and immunosuppressive. Since, ZIKV infection is a major threat in pregnant women, their futuristic use as antiviral is untenable. Arbidol is a widely used antiviral that has been found to effectively inhibit ZIKV in mammalian cell lines, possibly at an early step in the viral lifecycle (Fink et al., 2018). Compared to these chemicals, our basil extract provides an alternative herbal option to fight against ZIKV outbreaks. In general, these natural products have least toxicity and thus provide a safer option to stop a virus that attacks the developing fetus.

Acknowledgments. The work is supported from indirect cost returns from a previous grant from the National Institutes of Health (AI39126) to Ayalew Mergia.

\section{References}

Adcock RS, Chu YK, Golden JE, Chung DH (2017): Evaluation of anti-Zika virus activities of broad-spectrum antivirals and NIH clinical collection compounds using a cell-based, high-throughput screen assay. Antiviral Res. 138, 47-56. https://doi.org/10.1016/j.antiviral.2016.11.018

Aliota MT, Bassit L, Bradrick SS, Cox B, Garcia-Blanco MA, Gavegnano C, Friedrich TC, Golos TG, Griffin DE, Haddow AD, Kallas EG, Kitron U, Lecuit M, Magnani DM, Marrs C, Mercer N, McSweegan E, Ng LFP, O'Connor DH, Osorio JE, Ribeiro GS, Ricciardi M, Rossi SL, Saade G, Schinazi RF, Schott-Lerner GO, Shan C, Shi PY, Watkins DI, Vasilakis N, Weaver SC (2017): Zika in the Americas, year 2:
What have we learned? What gaps remain? A report from the Global Virus Network. Antiviral Res. 144, 223-246. https://doi.org/10.1016/j.antiviral.2017.06.001

Barrows NJ, Campos RK, Powell ST, Prasanth KR, Schott-Lerner G, Soto-Acosta R, Galarza-Munoz G, McGrath EL, UrrabazGarza R, Gao J, Wu P, Menon R, Saade G, Fernandez-Salas I, Rossi SL, Vasilakis N, Routh A, Bradrick SS, GarciaBlanco MA (2016): A Screen of FDA-Approved Drugs for Inhibitors of Zika Virus Infection. Cell Host Microbe 20,259-270. https://doi.org/10.1016/j.chom.2016.07.004

Cao-Lormeau VM, Blake A, Mons S, Lastere S, Roche C, Vanhomwegen J, Dub T, Baudouin L, Teissier A, Larre P, Vial AL, Decam C, Choumet V, Halstead SK, Willison HJ, Musset L, Manuguerra JC, Despres P, Fournier E, Mallet HP, Musso D, Fontanet A, Neil J, Ghawche F (2016): Guillain-Barre Syndrome outbreak associated with Zika virus infection in French Polynesia: a case-control study. Lancet 387, 1531-1539. https://doi.org/10.1016/S01406736(16)00562-6

Chan JF, Yip CC, Tsang JO, Tee KM, Cai JP, Chik KK, Zhu Z, Chan CC, Choi GK, Sridhar S, Zhang AJ, Lu G, Chiu K, Lo AC, Tsao SW, Kok KH, Jin DY, Chan KH, Yuen KY (2016): Differential cell line susceptibility to the emerging Zika virus: implications for disease pathogenesis, non-vector-borne human transmission and animal reservoirs. Emerg. Microbes Infect. 5, e93. https://doi.org/10.1038/emi.2016.99

Chiang LC, Ng LT, Cheng PW, Chiang W, Lin CC (2005): Antiviral activities of extracts and selected pure constituents of Ocimum basilicum. Clin. Exp. Pharmacol. Physiol. 32, 811816. https://doi.org/10.1111/j.1440-1681.2005.04270.x

Fink SL, Vojtech L, Wagoner J, Slivinski NSJ, Jackson KJ, Wang R, Khadka S, Luthra P, Basler CF, Polyak SJ (2018): The antiviral drug arbidol inhibits Zika virus. Scientific Reports 8, 8989. https://doi.org/10.1038/s41598-018-27224-4

Gavanji SS, Larkia B, Bakhtari A (2015): Antiviral activity of some plant oils against herpes simplex virus type 1 in Vero cell culture. J. Acute Medicine 5, 62-68. https://doi. org/10.1016/j.jacme.2015.07.001

Green LM, Reade JL, Ware CF (1984): Rapid colorimetric assay for cell viability: application to the quantitation of cytotoxic and growth inhibitory lymphokines. J. Immunol. Methods 70, 257-268. https://doi.org/10.1016/00221759(84)90190-X

Khalil A (2013): Antimicrobial activity of ethanolic extracts of Ocimum basilicum leaf from Saudi Arabia. Biotechnol. 12, 61-64. https://doi.org/10.3923/biotech.2013.61.64

Marwat SK, Rehman FU, Khan MS, Ghulam S, Anwar N, Mustafa G (2011): Phytochemical constituents and pharmacological activities of sweet basil-ocimum basilicum L. (Lamiaceae). Asian J. Chem. 23, 3773-3782.

Oehler E, Watrin L, Larre P, Leparc-Goffart I, Lastere S, Valour F, Baudouin L, Mallet H, Musso D, Ghawche F (2014): Zika virus infection complicated by Guillain-Barre syndromecase report, French Polynesia, December 2013. Euro Surveill. 19, pii: 20720. https://doi.org/10.2807/1560-7917. ES2014.19.9.20720

Pandey AK, Singh P, Tripathi NN (2014): Chemistry and bioactivities of essential oils of some Ocimum species: an overview. 
Asian Pacific J. Trop. Biomed. 4, 682-694. https://doi. org/10.12980/APJTB.4.2014C77

Roy A, Chakraborty P, Polley S, Chattopadhyay D, Roy S (2013): A peptide targeted against phosphoprotein and leader RNxA interaction inhibits growth of Chandipura virus - an emerging rhabdovirus. Antiviral Res. 100, 346-355. https://doi.org/10.1016/j.antiviral.2013.09.003
Suppakul P, Miltz J, Sonneveld K, Bigger SW (2003): Antimicrobial properties of basil and its possible application in food packaging. J. Agricult. Food Chem. 21, 3197-3207. https://doi.org/10.1021/jf021038t

Ventura CV, Maia M, Bravo-Filho V, Gois AL, Belfort R Jr (2016): Zika virus in Brazil and macular atrophy in a child with microcephaly. Lancet 387, 228. https://doi.org/10.1016/ S0140-6736(16)00006-4 